\title{
Decreased level of antibodies against Helicobacter pylori in patients with rheumatoid arthritis receiving intramuscular gold
}

Matthijs Janssen, Ben A C Dijkmans, Jan P Vandenbroucke, Wim van Duijn, Amado S Peña, Cornelius B H W Lamers

\begin{abstract}
Background Sodium aurothiomalate has been reported to have in vitro activity against Helicobacter pylori. Intramuscular gold, as given to patients with rheumatoid arthritis (RA), may therefore influence the colonisation of the gastric mucosa with $H$ pylori.

Methods Two groups were compared. One group of 42 patients was treated with intramuscular gold; the other group of $\mathbf{5 8}$ patients was treated with antimalarial drugs. Antibodies to $H$ pylori (IgA and IgG) were assessed by an enzyme linked immunosorbent assay (ELISA) and total IgA and IgG were measured by nephelometry.

Results IgA and IgG antibody titres against $H$ pylori and total IgA and IgG levels were lower in the patients treated with gold than in the group treated with antimalarial drugs. The ratio of IgA antibodies to $H$ pylori to total IgA antibodies and the ratio of IgG antibodies to $\boldsymbol{H}$ pylori to total IgG antibodies were lower in the group treated with gold. The percentage of seropositivity to $H$ pylori was significantly lower in the group treated with gold than in the group treated with antimalarial drugs for the two IgA antibodies (35 and $55 \%$ respectively) and IgG antibodies to $H$ pylori (40 and 65\% respectively).

Conclusions Although this study cannot completely exclude the possibility that a suppressive effect of intramuscular gold on total immunoglobulin production plays a part in the decrease in the titres of IgA antibodies to $H$ pylori and IgG antibodies to $H$ pylori, the lower ratios of antibodies to $H$ pylori to total immunoglobulin antibodies and the lower percentages of seropositivity to $H$ pylori in the group treated with gold suggests that treatment with intramuscular gold decreases $H$ pylori colonisation.
\end{abstract}

(Ann Rheum Dis 1992; 51: 1036-1038)

The presence of Helicobacter pylori in the gastric mucosa is responsible for most cases of gastritis and may be a major factor in the pathogenesis of peptic ulcer disease. ${ }^{1}$ Seropositivity to $H$ pylori, an indication for the presence of this bacteria in the mucosa, ${ }^{2}$ is found world wide in $35-86 \%$ of patients with a 'classical' gastric ulcer and in $75-100 \%$ of patients with a 'classical' duodenal ulcer. ${ }^{2}$ The role of $H$ pylori in the pathogenesis of ulcer disease associated with the use of nonsteroidal anti-inflammatory drugs (NSAIDs) remains controversial, however. ${ }^{3}{ }^{4}$ The pathophysiology of NSAID associated ulcer disease entails the inhibition of prostaglandin synthesis with loss of cytoprotection, inhibition of gastric mucus and gastric hydrogen carbonate secretion, and a decrease in mucosal blood flow, in addition to possible role of $H$ pylori. ${ }^{25}$ It is speculated that two types of NSAID associated ulcers exist: ulcers that occur de novo in histologically normal gastric mucosa, and those due to the exacerbation by NSAIDs of an underlying peptic diathesis--the latter presumably distinguished from the former by the presence of antral gastritis and $H$ pylori colonisation. ${ }^{6}$

Heavy metals such as gold and bismuth salts have long been used for the treatment of bacterial infections. ${ }^{27}$ Treatment with bismuth salts cleared $H$ pylori infection in many patients ${ }^{8}$ and sodium aurothiomalate has been found to have in vitro activity against $H$ pylori. ${ }^{9}$ This leads to the suggestion that intramuscular gold may influence the colonisation of the gastric mucosa with $H$ pylori. Therefore we compared the levels of antibodies against this bacteria in patients with rheumatoid arthritis $(R A)$ receiving intramuscular gold with those in patients with $R A$ receiving antimalarial drugs who had never been treated with intramuscular gold.

\section{Patients and methods}

One hundred consecutive patients with RA attending the outpatient clinic of the department of rheumatology and treated for at least six months with Auromyose (50 mg weekly), a suspension of aurothioglucose in oil $(n=42)$, or antimalarial drugs (hydroxychloroquine 200 mg daily; $n=58$ ) were included in the study. None of the patients receiving antimalarial drugs has ever been treated with gold salts. None of the patients receiving intramuscular gold were currently treated with antimalarial drugs and none of the patients had been treated with bismuth salts. None of the patients had had an active peptic ulcer in the previous three months. We recorded the following information from the patients: age, gender, presence of rheumatoid factors, duration of the disease, current use of NSAIDs or gastric drugs, and history of peptic ulcer disease as established by barium meal, radiography, or gastroscopy. After informed consent blood samples were obtained to measure the titre of antibodies to $H$ pylori and total serum IgA and IgG levels. Serum IgA and IgG levels were measured by rate nephelometry (Beckmann), ${ }^{10}$ and IgG and IgA antibodies to $H$ pylori were measured by an enzyme linked immunosorbent assay (ELISA), as described in detail elsewhere. ${ }^{11}$ In our analysis we used the absolute values for IgA and 
IgG antibodies against $H$ pylori and the cutoff point for seropositivity to $H$ pylori, which is the absorption index (AI) $(0.32$ and 0.35 for antibodies of IgG and IgA respectively). The sensitivity, specificity, and positive and negative predictive values for the presence in the mucosa of $H$ pylori in our method for IgG antibodies were $89,88,89$, and 88 , and for IgA antibodies they were $78,88,88$, and $79 \% .{ }^{8}$ As it is known that during treatment with gold the total serum IgA and IgG levels decrease ${ }^{12}{ }^{13}$ we had to correct for this possible confounder of the results by calculating the ratio of IgG antibodies to $H$ pylori to total IgG and the ratio of IgA antibodies to $H$ pylori to total IgA.

For comparison between groups use was made of the $\chi^{2}$ test with Yates's correction or of the Wilcoxon signed rank test.

\section{Results}

Table 1 shows that the two groups were well balanced with respect to gender, age, and presence of rheumatoid factor. The disease duration was longer in the group treated with gold than in the group treated with antimalarial drugs, which can be explained by the policy of our department to give antimalarial drugs before intramuscular gold. Current use of NSAIDs and gastric drugs was the same for the two groups as was the history of peptic ulcer disease (table 1). In the group treated with gold three patients had had a duodenal ulcer (one

Table 1 Demographic data, duration of disease, presence of rheumatoid factor, current use of non-steroidal anti-inflammatory drugs (NSAIDs) or gastric drugs, and history of gastric or duodenal ulcer in two groups of patients with rheumatoid arthritis

\begin{tabular}{llll}
\hline & Patient group & & $\begin{array}{l}\text { Difference } \\
\text { between two } \\
\text { groups }\end{array}$ \\
\cline { 2 - 4 } & $\begin{array}{l}\text { Intramuscular gold } \\
(n=42)\end{array}$ & $\begin{array}{l}\text { Antimalarial drugs } \\
(n=58)\end{array}$ & \\
\hline Gender (M/F) & $22 / 20$ & $20 / 38$ & NS* \\
Age (years) & $56 \cdot 3(14 \cdot 4 ; 18-78) \dagger$ & $56 \cdot 2(13 \cdot 4 ; 18-77)$ & NS \\
Duration of disease (years) & $9(7 \cdot 1 ; 1-29)$ & $5(5 \cdot 7 ; 1-25)$ & $0 \cdot 06$ \\
Rheumatoid factor positive (\%) & 86 & 71 & NS \\
Current use of NSAIDs (\%) & 90 & 81 & NS \\
Current use of gastric drugs (\%) & 20 & 22 & NS \\
History of duodenal ulcer (\%) & 7 & 5 & NS \\
History of gastric ulcer (\%) & 5 & 12 &
\end{tabular}

${ }^{*} \mathrm{NS}=$ not significant.

+Mean (SD; range).

Table 2 Levels of antibodies against Helicobacter pylori, total level of immunoglobulins, and ratio of antibodies to $H$ pylori to total Ig antibodies in two groups of patients with rheumatoid arthritis

\begin{tabular}{|c|c|c|c|}
\hline \multirow[t]{2}{*}{ Parameter } & \multicolumn{2}{|l|}{ Patient group } & \multirow{2}{*}{$\begin{array}{l}\text { Difference } \\
\text { between two } \\
\text { groups }\end{array}$} \\
\hline & $\begin{array}{l}\text { Intramuscular gold } \\
(n=42)\end{array}$ & $\begin{array}{l}\text { Antimalarial drugs } \\
(n=58)\end{array}$ & \\
\hline $\begin{array}{l}\text { Titre of IgA antibodies to } H \text { pylori } \\
\text { (absorption index) } \\
\text { Total IgA (g/l) } \\
\text { Ratio of IgA antibodies to } H \text { pylori } \\
\text { to total IgA antibodies } \\
\text { Titre of IgG antibodies to } H \text { pylori } \\
\text { (absorption index) } \\
\text { Total IgG (g/l) } \\
\text { Ratio of IgG antibodies to } H \text { pylori } \\
\text { to total IgG antibodies } \\
\text { Positivity to IgA antibodies to } \\
H \text { pylori }(\%) \\
\text { Positivity to IgG antibodies to } \\
H \text { pylori (\%) } \\
\text { Total positivity (\%) }\end{array}$ & $\begin{array}{l}0.39(0.41)^{*} \\
2 \cdot 4(1.3) \\
0.019(0.023) \\
0.34(0.31) \\
11 \cdot 7(3.5) \\
0.035(0.036) \\
35 \\
40 \\
42\end{array}$ & $\begin{array}{l}0.58(0.41) \\
3.1(1.6) \\
0.025(0.019) \\
0.47(0.35) \\
13 \cdot 2(4 \cdot 2) \\
0.041(0.031) \\
55 \\
65 \\
67\end{array}$ & $\begin{array}{l}p<0.005 \\
p<0.05 \\
\text { NS } \\
\text { NS } \\
\text { SS } \\
\text { NS } \\
p<0.05 \\
p<0.01 \\
p<0.01\end{array}$ \\
\hline
\end{tabular}

"Median (SD). seronegative and two seropositive to $H$ pylori) and two a gastric ulcer (one seronegative and one seropositive to $H$ pylori). In the group treated with antimalarial drugs three patients had had a duodenal ulcer (all seropositive to $H$ pylori) and seven patients had had a gastric ulcer (one seronegative and six seropositive to $H$ pylori). Gastric drugs were used by eight patients (one antacids, seven $\mathrm{H}_{2}$ antagonists) in the group treated with gold (two seronegative and six seropositive to $H$ pylori) and by 13 patients (six antacids, seven $\mathrm{H}_{2}$ antagonists; two seronegative and 11 seropositive to $H$ pylori) in the group treated with antimalarial drugs.

The mean titre of antibodies to $H$ pylori was lower in the group treated with gold than in the group treated with antimalarial drugs; the difference between the groups for IgA antibodies was statistically significant $(p<0.005$; table 2$)$. The mean titre of total IgA and IgG antibodies was lower in the group treated with gold than in the group treated with antimalarial drugs; the difference between the groups for IgA antibodies was statistically significant $(p<0.05$; table 2). In addition the ratio of immunoglobulin antibodies to $H$ pylori to total imnunoglobulin antibodies was lower in the group treated with gold but the difference was no longer significant.

The percentage of seropositivity to $H$ pylori, as defined by the given cutoff points, was significantly lower in the group treated with gold than in the group treated with antimalarial drugs for IgA and IgG antibodies and for the combination of both (table 2).

\section{Discussion}

The main conclusion to be drawn from this study is that the titre of antibodies to $H$ pylori and the percentage of seropositivity to $H$ pylori in a group of patients with RA treated with intramuscular gold is decreased compared with a group of patients with RA treated with antimalarial drugs. In this latter group the percentage seropositivity to $H$ pylori was as expected from their age. ${ }^{14}$ As the decreased titre of antibodies to $H$ pylori in the group treated with intramuscular gold could be ascribed to a non-specific effect of this drug, we compared the ratios of antibodies to $H$ pylori and total immunoglobulin between the groups treated with gold and antimalarial drugs. Lower ratios in the group treated with gold were found. The lower ratios in the group treated with gold suggested that the decrease in the titres of antibodies to $H$ pylori cannot only be ascribed to an overall effect of gold. ${ }^{12}{ }^{13}$ As there is a strong correlation between seropositivity to $H$ pylori and the presence of this bacteria in the gastric mucosa ${ }^{11}$ the decreased seropositivity in the group treated with gold also indicates a decreased colonisation of the gastric mucosa with $H$ pylori. Patients with a history of peptic ulcer disease who are seronegative to $H$ pylori are more often found in the group treated with gold. One explanation could be that these patients became seronegative to $H$ pylori during gold treatment; another explanation is that NSAID associated ulcers can occur without a $H$ pylori infection. ${ }^{34}$ 
Further studies are necessary to investigate whether intramuscular gold, which is known to penetrate into numerous tissues, ${ }^{15}$ has indeed antibacterial activity in the gastric mucosa to $H$ pylori in vivo, and finally leads to a decreased occurrence of gastric and duodenal ulcers. As a complement to pathophysiological studies epidemiological surveys are needed to assess whether ulcer disease occurs in a lower percentage of patients with RA treated with intramuscular gold than in patients with RA receiving other remittive drugs. The results of Singh et al, ${ }^{16}$ studying toxicity profiles of disease modifying drugs in RA, indicate a surprisingly low percentage of upper gastrointestinal tract disease in patients with RA receiving intramuscular gold in contrast with patients treated with other second line drugs.

In contrast with the declining prevalence of ulcer disease in the $1960 \mathrm{~s}$ and $1970 \mathrm{~s},{ }^{17}$ the frequency of this disease in elderly patients increases ${ }^{18}$ leading to many published studies. Circumstantial evidence from many studies indicates that the increase in ulcer disease can be ascribed to the increase of NSAID use. ${ }^{19}$ Attempts have been made to characterise the patient at risk of developing a NSAID gastropathy. At present risk groups for peptic ulcer disease are identified on epidemiological grounds and include elderly patients, especially women, patients with previous ulcer disease, and use of more than one NSAID concomitantly. ${ }^{20}$ Based on the profile of the patient at risk preventive measures are advocated in particular concomitant treatment with cytoprotective drugs. Our findings, however, may shed new light on the problem of NSAID gastropathy, especially in RA, with respect to intramuscular gold. With the increased use of several remittive drugs (sulphasalazine, methotrexate) even early in the course of RA, intramuscular gold may have been used only later in the disease course or not used at all. Moreover because of its side effects rheumatologists have reservations about giving intramuscular gold to elderly patients who, in fact, are most at risk of peptic ulcer disease.

On the assumption that intramuscular gold protects against ulcer disease, a decreased use of this treatment may have been a factor in the increased occurrence of peptic ulcer disease. This study indicates that in contrast to the risk factors a possible protective factor might play an important part in the changing incidence of ulcer disease in patients with RA. As an additional consequence of our hypothesis, patients with RA receiving intramuscular gold are likely to need gastric protective drugs less often.

In conclusion patients with $\mathrm{RA}$ receiving intramuscular gold have decreased levels of antibodies and decreased seropositivity to $H$ pylori. Intramuscular gold might therefore be a protective factor for ulcer disease. Whi. . prospective studies in patients with RA confiris this suggestion the findings of the present study may force us to reconsider the place of intramuscular gold and gastric protective drugs in the treatment of patients with RA.

We are indebted to Professor Dr F C Breedveld for his critical comments and to $\mathrm{Dr} R$ van Wengen-Shute for correcting the English manuscript.

1 Peterson W L. Helicobacter pylori and peptic ulcer disease. N Engl f Med 1991; 324: 1043-8.

2 Blaser $M \mathrm{~J}$. Helicobacter pylori and the pathogenesis of gastroduodenal inflammation. F Infect Dis 1990; 161: 626-63.

3 Shallcross T M, Rathbone B J, Wyatt J I, Heatly R V. Helicobacter pylori associated chronic gastritis and peptic ulceration in patients taking non-steroidal anti-inflammatory drugs. Aliment Pharmacol Therap 1990; 4: 515-22.

4 Feldman $M$. Helicobacter pylori and the etiology of duodenal ulcer: necessary but not sufficient. Am F Med 1991; 91: ulcer: nece

5 Schoen R T, Vender R J. Mechanisms of nonsteroidal antiinflammatory drug-induced gastric damage. $A m \mathcal{J} \mathrm{Med}$ 1989; 86: 449-58.

6 Soll A H. Pathogenesis of peptic ulcer and implications for therapy. $N$ Engl f Med 1990; 322: 909-16.

7 Keers R Y. The gold rush 1925-35. Thorax 1980; 35: 884-9.

8 Rauws E A J, Langenberg W, Houthoff H J, Zanen H C. Tytgat G N J. Campylobacter pyloridis-associated chronic active antral gastritis. Gastroenterology 1988; 94: 33-40.

9 Braga L L, Sarosiek J, Marshall B, McCallum R W, Barett L, Guerrant R. Gold: a new potential drug for the treatment of helicobacter pylori infection [abstract]. Gastroenterology 1990; 98: A25.

10 Deaton C D, Maxwell K W, Smith R S, Reveling R L. Use of laser nephelometry in the measurement of serum proteins. Clin Chem 1976; 22: 1465-71.

11 Peña A S, Endtz H P H, Offerhaus G J A, et al. Value of serology (ELISA and immunoblotting) for the diagnosis of Campylobacter pylori infection. Digestion 1989; 44: 131-41.

12 Hanly J G, Hassan J, Whelan A, Feighery C, Bernihan B. Effects of gold therapy on the syntheses and quantity of serum and synovial fluid IgM, IgG, and IgA rheumatoid factors in rheumatoid arthritis patients. Arthritis Rheum 1986; 29: 480-7.

13 Lorber A, Simon T, Leed J, Peter A, Wilcox S. Chrysotherapy; suppression of immunoglobulin synthesis. Arthritis Rheum 1978; 21: 785-91.

14 Perez-Perez G I, Dworkin B, Chodos J, Blaser M J. Campylobacter pylori-specific serum antibodies in humans. Ann Intern Med 1988; 109: 11-7.

15 Gottlieb N L, Smith P M, Smith E M. Tissue gold concentration in a rheumatoid arthritic receiving chrysotherapy. Arthritis Rheum 1972; 15: 16-22.

16 Singh G, Fries J F, Williams C A, Zatarain E, Spitz P, Bloch D A. Toxicity profiles of disease modifying drugs in rheumatoid arthritis. $\mathcal{F}$ R heumatol $1991 ; 18$ : 188-94.

17 Kurata J H. What in the world is happening to ulcers? Gastroenterology 1983; 84: 1623-5.

18 Laporte J R, Carné X, Vidal X, Moreno V, Juan J. Upper gastrointestinal bleeding in relation to previous use of analgesics and non-steroidal anti-inflammatory drugs. Lancet 1991; 337: 85-9.

19 Langman M J S. Epidemiologic evidence on the association between peptic ulceration and antiinflammatory drug use. between peptic ulceration and an

20 Roth S H, Bennett R E. Non-steroidal anti-inflammatory drug gastropathy. Arch Intern Med 1987; 147: 2093-100. 